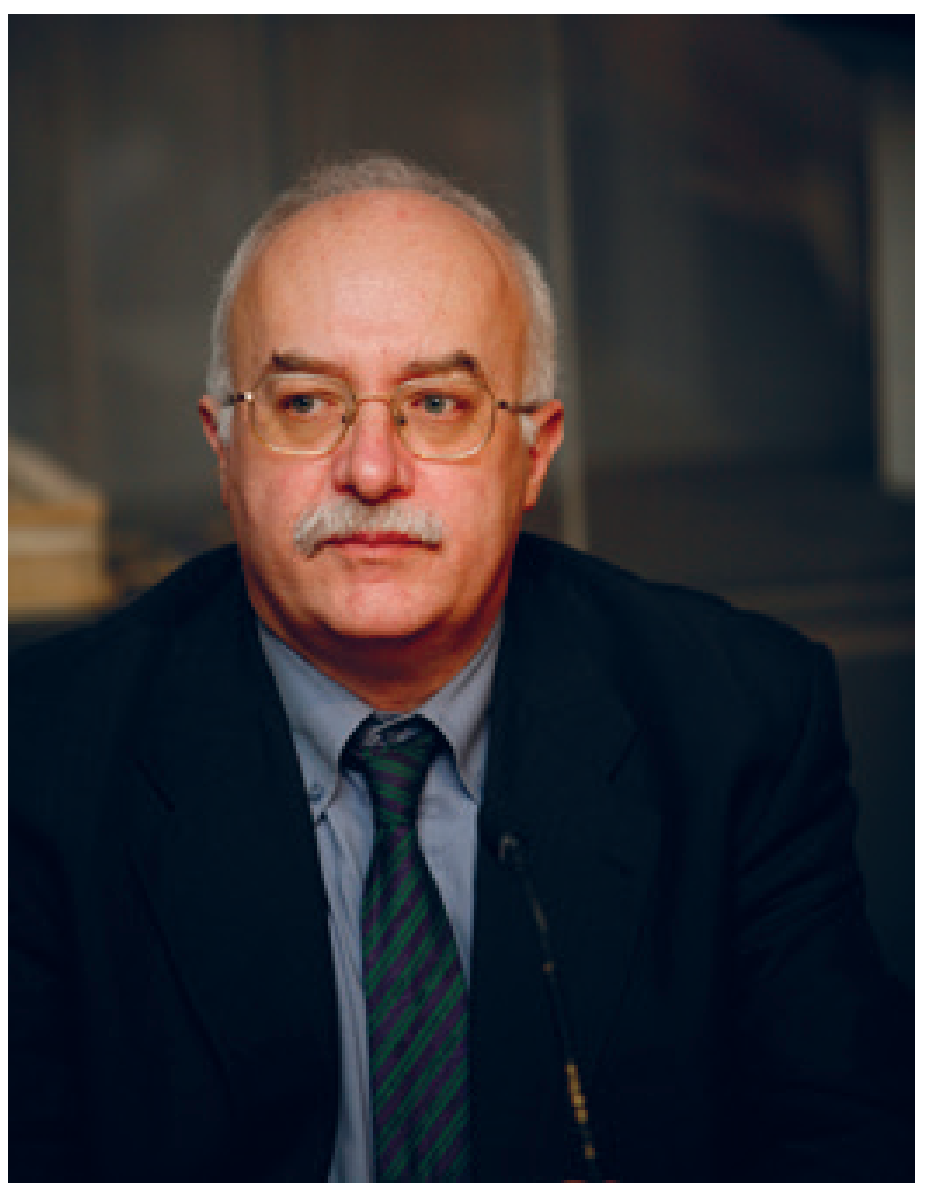

Juan Calatrava Escobar

Durante la segunda mitad del siglo XX, un número importante de editoriales latinoamericanas y españolas consagraron en alguna colección de arte o de arquitectura el espacio para publicar traducciones ya no sólo de textos de arquitectos, sino también de aquellos de autores que ejercieron una enorme influencia en el desarrollo de la historia, de la teoría y de la crítica: Giedion, Pevsner, Zevi, Benevolo, Banham, Tafuri, y muchos otros llegaron así a manos de los lectores hispanohablantes. Esto fue posible gracias a la iniciativa de los traductores que desde su rol de passeurs materializaron progresivamente su voluntad de hacer accesibles aquellos libros, obedeciendo así a lo que concebían como un deber científico y profesional.

Así, en el medio hispanófono, la traducción "masiva" de este tipo de textos fue posible gracias a editoriales como Gustavo Gili, Poseidón, Infinito o Nueva Visión, que desempeñaron desde los años 1940 y 1950 un papel fundamental en la difusión de libros escritos originalmente en lenguas como el inglés, el francés, el italiano y el alemán, y que al ser traducidos entraron a formar rápidamente parte esencial de las bibliotecas universitarias, y por supuesto de las bibliotecas

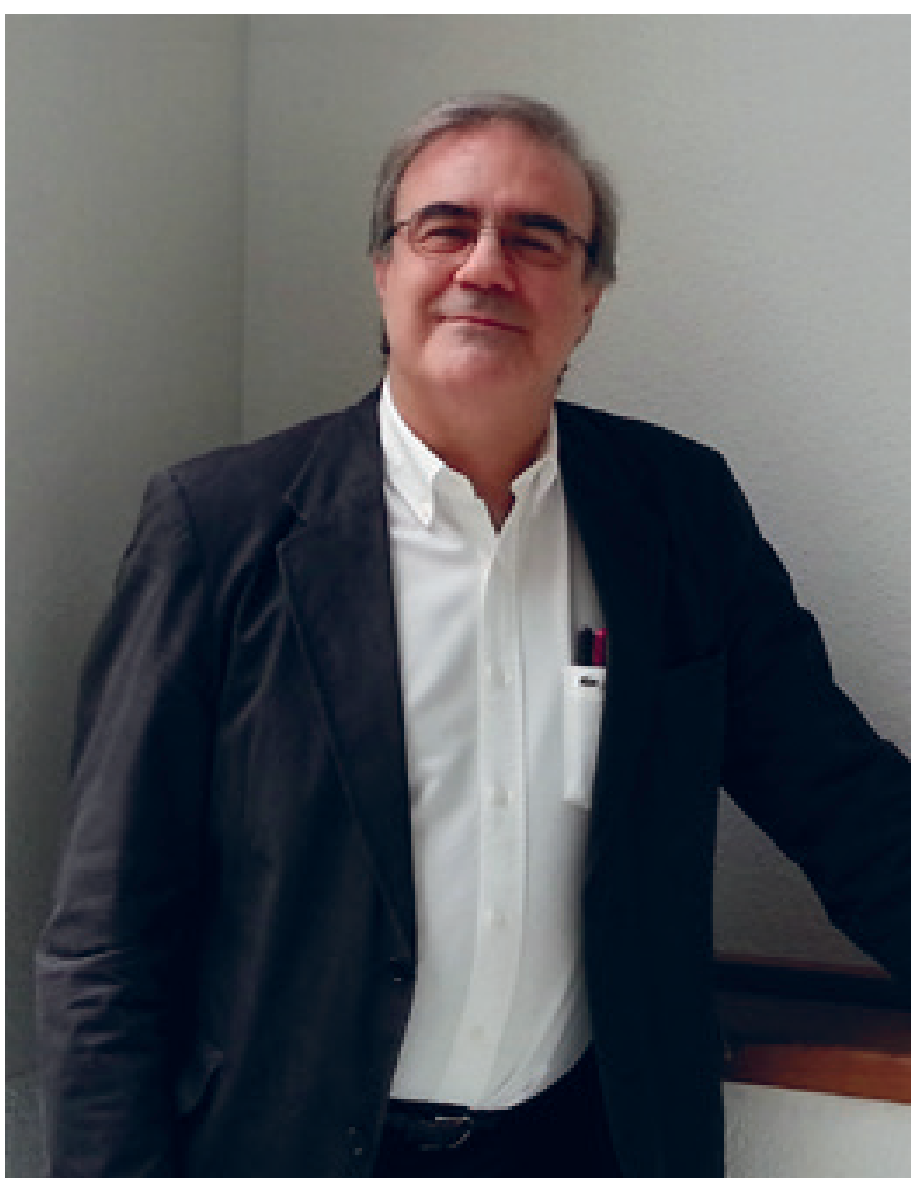

Jorge Sainz Avia

privadas de profesionales, profesores y estudiantes de estas disciplinas por toda Hispanoamérica.

El propósito de las dos entrevistas que presentamos a continuación es triple: antes que nada, visibilizar y valorizar un oficio hasta ahora poco o nada reconocido entre los propios arquitectos, pero vital para la construcción de la cultura arquitectónica. En segunda instancia, resaltar de manera puntual la tarea de dos arquitectos que además de desarrollar otras facetas propias de la disciplina -principalmente la enseñanza y la investigación-, han traducido al español varias decenas de obras fundamentales, y han impulsado la traducción especializada durante las dos últimas décadas como directores de prestigiosas colecciones de arquitectura en España: Juan Calatrava Escobar y Jorge Sainz Avia. Por último, esperamos que tanto nuestras preguntas como los valiosos testimonios de los entrevistados aporten elementos claves que guíen posteriores investigaciones en torno al fenómeno de la traducción especializada en el ámbito de la arquitectura y del urbanismo, y que contribuyan a esclarecer las dinámicas que han determinado la selección de los textos traducidos -o no- para su publicación por parte de editoria- 


\title{
Traducir la arquitectura. El arquitecto y el oficio de la traducción. Entrevistas a Juan Calatrava Escobar y Jorge Sainz Avia
}

\author{
Translating Architecture. \\ Architects on Translation. Interviews \\ with Juan Calatrava Escobar \\ and Jorge Sainz Avia
}

\author{
ANDRÉS ÁVILA GÓMEZ
}

Andrés Ávila Gómez "Traducir la arquitectura. El arquitecto y el oficio de la traducción. Entrevistas a Juan Calatrava Escobar y Jorge Sainz Avia" ZARCH 10 (Junio 2018): 224-237 ISSN: 2341-0531. https://doi.org/10.26754/ojs_zarch/zarch.2018102943

les hispanoamericanas; con lo cual se podrá reconstruir esta historia transnacional sobre la actividad de aquellos traductores que viniendo de diversas disciplinas -la literatura, el periodismo, la historia del arte, etc.- han potenciado esta modalidad especifica de transferencia cultural.

¿Cuáles son los idiomas que usted domina, y como adquirió su conocimiento?

JCE. El francés y el italiano puede decirse que correctamente; de hecho, habitualmente imparto cursos y conferencias en ambos idiomas. Con el inglés, no tengo grandes problemas a nivel de lectura, pero sí muchas dificultades en la conversación, y, aunque alguna vez no me ha quedado más remedio que hacer una intervención pública en ese idioma, siempre me ha quedado la molesta sensación de haber hecho el ridículo. Con respecto al alemán, mi conocimiento es muy elemental, aunque lo suficiente como para leer, dificultosamente, textos de mi materia. El conocimiento básico del francés se lo debo a mis estudios de bachillerato ya que, en mi época, lo normal en los colegios era estudiar francés y el inglés era una rareza; aunque el verdadero dominio de la lengua lo adquirí después a base de numerosos viajes y estancias en Francia y por supuesto debido a mi continua labor de traductor. En italiano, empecé de manera autodidacta, sobre todo leyendo mucho, pero he llegado a hablarlo bien -o al menos eso me dicen amablemente mis amigos italianos-, gracias también a mis frecuentes estancias docentes o de investigación en Italia.

JSA. En el colegio empecé estudiando francés, pero enseguida me cambiaron a inglés. No obstante, esto me dio tiempo para aprender los rudimentos de la lengua francesa, que luego estudié en el Institut Français de Madrid, y también por mi cuenta. Leo con fluidez escritos de arquitectura y puedo traducir textos breves. El inglés es la lengua que mejor conozco y de la que más he traducido: lo estudié en el bachillerato y en varias academias, pero nunca en un país de lengua inglesa, por lo que no tengo fluidez para entenderlo oralmente ni para hablarlo; en cambio, lo leo, lo escribo y lo traduzco perfectamente. El italiano es mi segunda lengua: la empecé a estudiar muy tarde, en 1983, en el Istituto Italiano di Cultura de Madrid, seguí en la Scuola Lorenzo de Medici, en Florencia, y terminé de aprenderlo en una estancia de seis meses 


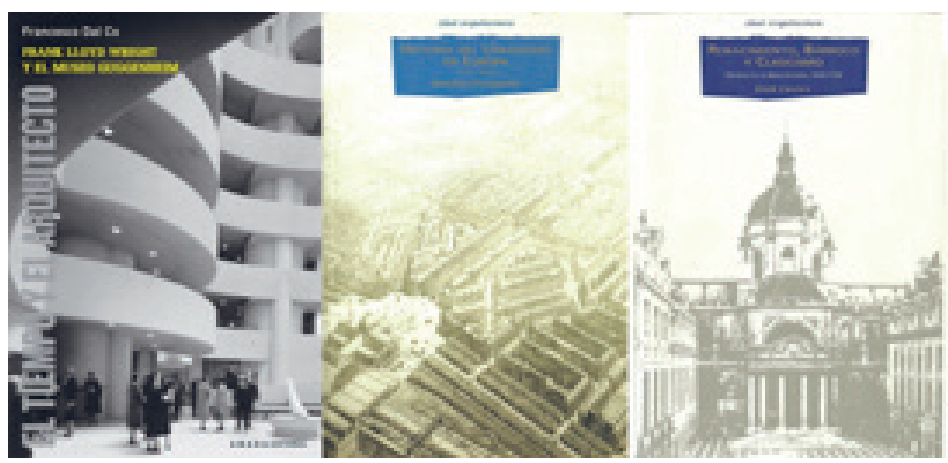

[Fig. 1] Portadas de traducciones realizadas por Juan Calatrava Escobar.

en la Università degli Studi La Sapienza, en Roma, donde ejercí como profesor invitado. El alemán lo estudié durante unos años en el Goethe Institut de Madrid, pero sólo alcancé el Grundstufe o nivel elemental. Sólo puedo resolver problemas sencillos de traducción de términos sueltos.

\section{¿Cuál fue la primera traducción al español, incluso no publicada, que realizó de un texto sobre historia o teoría de la arquitectura?}

JCE. La traducción que realicé en 1979 para la editorial Akal de un conjunto de estudios de autores como Giulio Carlo Argan, Rosario Assunto, Manfredo Tafuri y Pierre Francastel, que apareció con el título global de Arte, arquitectura y estética en el siglo XVIII. Fue una propuesta mía al editor. Yo mismo seleccioné una serie de escritos, que me parecían de gran interés y que tenían relación directa con la tesis doctoral que por entonces estaba elaborando (sobre la teoría de la arquitectura y el arte en la Encyclopédie de Diderot) y redacté una pequeña introducción, que es una de mis primeras publicaciones. El editor, Ramón Akal, para quien ya había realizado algunas traducciones, sobre todo de historia antigua y medieval, aceptó la idea y, para mi sorpresa, fue un librito que en su momento tuvo mucha difusión y me dio a conocer bastante bien dentro del mundillo académico cuando apenas acababa de terminar la carrera.

JSA. Durante los estudios universitarios (1972-1978), manejábamos revistas y libros en inglés e italiano. Tradujimos algunos textos para nuestra propia formación, de los cuales he encontrado archivado Meaning in Western architecture, de Christian Norberg-Schulz ${ }^{1}$ (Londres: Studio Vista, 1975).

1 Setradujeron : el Prefacio (manuscrito de JSA); el Capítulo 2: "La arquitectura griega" (manuscrito de JSA); el Capítulo 9: "La arquitectura barroca" (mecanográfico de JSA); el Capítulo 12: "Pluralismo" (mecanográfico de Fernando Valderrama); el Epílogo. "Significado..." (mecanográfico de Fernando Valderrama).

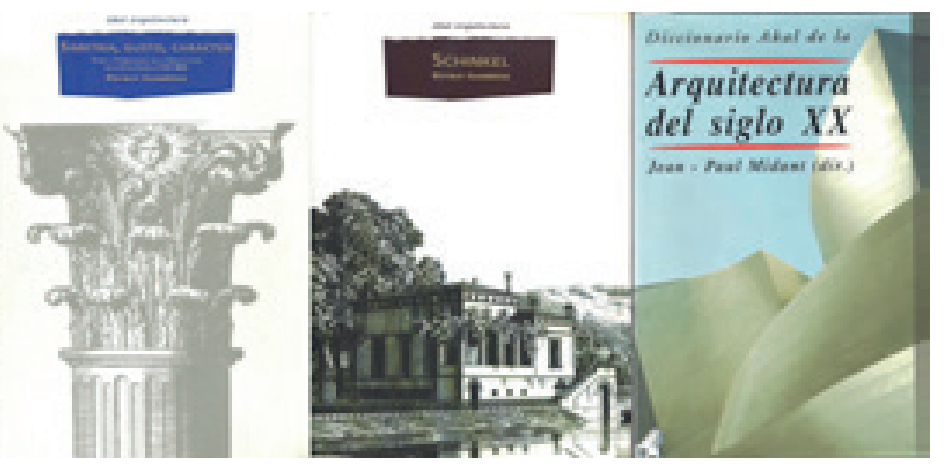

Cuando mi compañero Fernando González Fernández de Valderrama y yo solicitamos trabajo de traducción a la editorial Hermann Blume en 1980, Luis Fernández-Galiano nos puso una "prueba" de italiano: el prólogo de Marcella delle Donne, Città-campagna: sociologia di una contraddizione (Roma: Savelli, 1975). Conservo los 14 folios de traducción; nunca se publicó en español. Aprobamos el "examen", pero los libros que nos encargó después estaban en inglés.

\section{¿Existió alguna situación o algún personaje en particu- lar que hubiesen propiciado, favorecido o estimulado sus inicios en el mundo de la traducción de textos espe- cializados?}

JCE. Cuando aún era estudiante, algunos de mis profesores universitarios realizaban ya traducciones para algunas editoriales especializadas, sobre todo para Akal que tan destacado papel desempeñó en aquellos años de la transición. En un momento de mucho trabajo solicitaron mi ayuda y traduje algunos capítulos de volúmenes colectivos de historia. Parece que mi labor fue bien apreciada, porque después de eso vinieron sucesivos encargos y poco a poco lo que en principio había surgido desde una motivación puramente económica fue convirtiéndose en una actividad también con un fuerte componente intelectual que cada vez me atraía más. En 1985 contacté por primera vez con la persona que por entonces se había hecho cargo de la dirección de ediciones Akal: Juan Barja, verdadero uomo universale: abogado, poeta, editor, gestor cultural, filósofo y actualmente director del Círculo de Bellas Artes de Madrid. Hoy es uno de mis mejores amigos y con él me une una estrecha complicidad intelectual que nos ha llevado a compartir muchos caminos e iniciativas. Por entonces, cuando todavía casi nos hablábamos de usted, me encargó algunas de las traducciones que más placer personal me han dado, como El Arte Italiano de André Chastel o Renacimiento y Barroco de Giulio Carlo Argan. 

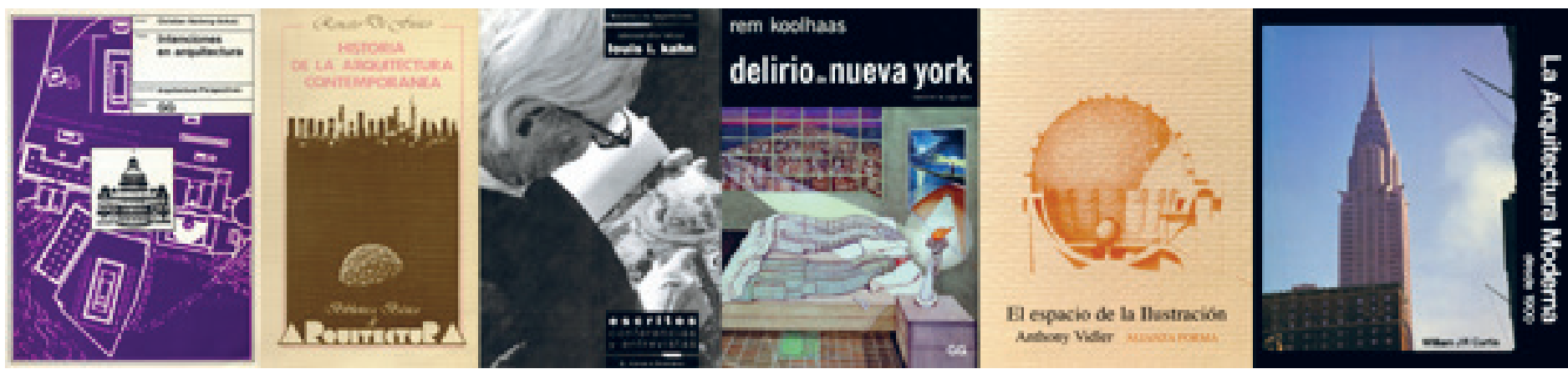

[Fig. 2] Portadas de traducciones realizadas por Jorge Sainz Avia.

JSA. Desde luego. La condición que propició mi dedicación a la traducción, y que me acercó también a la enseñanza y la edición, fue la situación de crisis total que había en España cuando terminé la carrera en 1978. Si hubiese encontrado trabajo como arquitecto "constructor", probablemente ahora no estaríamos escribiendo esto. Recién terminados los estudios, mi colega Fernando Valderrama y yo solicitamos una beca para estudiar con nuestro autor favorito: Christian Norberg-Schulz, que era profesor en Oslo. Le escribimos para contarle que estábamos traduciendo por nuestra cuenta su libro Intentions in architecture, aunque en realidad, la traducción la estaba haciendo sólo Fernando, como actividad veraniega. Muy amable, Norberg-Schulz nos respondió. No nos concedieron la beca, pero cuando la editorial Gustavo Gili decidió publicar ese libro en español, el autor les dio nuestra dirección... y nos encargaron la traducción. Así pues, Norberg-Schulz fue un personaje decisivo para que iniciásemos nuestra labor como traductores. La otra persona clave fue Luis Fernández-Galiano, hoy catedrático de Proyectos de la Escuela Técnica Superior de Arquitectura de Madrid y director de las revistas editadas por Arquitectura Viva, S.L. En 1978, Fernández-Galiano era el director de las colecciones de arquitectura de la editorial Hermann Blume, desaparecida en 1989. En respuesta a una carta nuestra ofreciéndonos como traductores, nos citó a Fernando y a mí para una entrevista y empezó a encargarnos traducciones. Gracias a él, la traducción se convirtió, en esos primeros años tras la carrera, en una actividad habitual, casi profesional, para nosotros.

¿Podría citar algunas de las principales razones por las cuales se vio atraído por el oficio de la traducción, y explicar si esto fue algo excepcional o recurrente dentro de su generación de colegas arquitectos?

JCE. Siempre me resultó un trabajo muy agradable: el reto de verter un texto desde su idioma original a otro para cuyos moldes no estaba pensado me parece un ejercicio apasionante y en absoluto tedioso ni mecánico, si lo quieres hacer bien. También es una labor, todo hay que decirlo, que considero relativamente rentable desde el punto de vista económico. Quienes en España se dedican a la traducción como profesión principal o única tienen razón, sin duda, cuando se quejan de la baja retribución de su labor: indicio, además, de un escaso aprecio general que lleva, por ejemplo, a que muy raramente aparezcan sus nombres en lugar destacado. Sin embargo, para mí esta actividad siempre ha sido complementaria y eso me permite decir que, desde un punto de vista muy personal, siempre he considerado que mis trabajos de traducción estaban razonablemente remunerados en relación al esfuerzo que invertía en ellos. Por supuesto, hay una tercera razón, que hace tiempo que ya se convirtió para mí en la principal, a medida que me podía ir permitiendo seleccionar cuidadosamente los textos que iba a traducir: cuando un libro te interesa verdaderamente, traducirlo es mucho más que leerlo, es algo que te permite reflexionar y profundizar en el pensamiento del autor de un modo muy diferente al de la simple lectura. Tengo que decir también, que mi alta valoración de la labor de traducción puede considerarse, lamentablemente, muy excepcional entre mis colegas de la docencia de la arquitectura, al menos los que yo he tratado. Salvo algún caso muy concreto, en general la tarea de traducción ha sido considerada en el mundo de la arquitectura como una actividad ciertamente necesaria pero de la que debían encargarse otros. A menudo, ha habido una cierta tendencia a considerar que, cuando un arquitecto o investigador en arquitectura traducía un libro, ello no dejaba de ser una pérdida de tiempo que le distraía de otros empeños de mayor categoría. Por todo lo que ya he dicho, es fácil comprender que yo nunca he compartido esta idea, y ello me ha costado alguna que otra discusión amistosa con colegas muy queridos que no entendían que tradujera libros de 
otros en lugar de escribir yo los míos, aunque he intentado siempre hacer ambas cosas.

JSA. Otra razón fundamental para haberme sentido atraído por la traducción es que tanto yo como mis compañeros de generación éramos ávidos lectores de libros de teoría e historia de la arquitectura. Por entonces, a finales de la década de 1970, ya se traducían algunos de esos libros, pero existían muchos más que nos llegaban sólo en su lengua original. Además, algunas de las traducciones publicadas por entonces nos parecían bastante deficientes, lo que nos animaba a intentar corregir esa situación. De mi grupo de compañeros más cercano, sólo Fernando Valderrama siguió haciendo traducciones durante algunos años, pero estaban tan mal pagadas que todo el mundo las abandonaba en cuanto encontraba otra actividad que permitiera ganarse la vida. Lo mismo ocurría con algunos de nuestros profesores más jóvenes: casi todos habían hecho alguna traducción al inicio de su trayectoria, pero luego lo habían abandonado.

¿Cuál fue la primera traducción al español importante que realizó de un texto sobre historia o teoría de la arquitectura, y que fue publicada y ampliamente difundida?

JCE. De mis primeras traducciones, gozaron de muy amplia difusión las que ya he citado antes de L'Art italien de André Chastel y de la Storia dell'arte italiana de Giulio Carlo Argan. También sucedió con mi versión de La divina proporción, de Luca Pacioli, un texto esencial, como es bien sabido, de la estética y la filosofía del Renacimiento: pese a su corta extensión, es sin duda la traducción que más trabajo me ha costado pulir y me permito decir que quedé muy satisfecho del resultado final.

JSA. La primera traducción publicada fue Intenciones en arquitectura de Norberg-Schulz (Gustavo Gili, 1980). La primera edición apareció en la colección "Arquitectura / Perspectivas". Posteriormente, se reimprimió en la colección "GG Reprints" en 1998. La iniciativa de hacer la traducción fue de Fernando Valderrama, quien empezó a traducir por su cuenta la versión inglesa publicada por The MIT Press en 1963. Luego contactamos con el autor, y éste comunicó a la editorial Gustavo Gili que nosotros estábamos traduciendo el libro. La editorial contactó con nosotros y nos pidió la traducción; se la fuimos enviando a medida que la revisábamos, porque en realidad lo que había era un borrador inacabado. Conservo toda la correspondencia con la editorial Gustavo Gili.

\section{¿De qué manera se dio su vinculación al mundo editorial especializado en temas de arquitectura y urbanismo?}

JCE. Mi labor de traductor fue consolidándose progresivamente desde mis primeros trabajos, realizados todavía en mi época de estudiante, hasta especializarme en textos de Arquitectura e Historia del Arte. Primero trabajé sobre todo para ediciones Akal y, posteriormente, cuando creamos Abada Editores, sobre todo para ésta última. He recibido encargos también de instituciones oficiales y de otras editoriales, aunque más ocasionalmente. Recuerdo con pena la traducción que realicé por encargo de Electa España del espléndido libro coordinado por Monique Mosser y Georges Teyssot L'architettura dei giardini d'Occidente, que finalmente nunca llegó a ver la luz; aunque la editorial cumplió escrupulosamente los términos económicos del contrato, es de lamentar que finalmente el lector español no pudiera beneficiarse de una obra fundamental en esta materia.

JSA. Mi primer contacto con las editoriales de arquitectura fue en 1979 a través de Luis Fernández-Galiano, de la editoria Hermann Blume (Madrid). Además de las traducciones, esta editorial aceptó publicar mi tesis doctoral en 1988, pero a los pocos meses el propietario falleció y la empresa se disolvió. Eso me hizo entrar en contacto con la editorial Nerea [por entonces en Madrid y ahora radicada en San Sebastián] que finalmente publicó mi tesis en 1990 con el título El dibujo de arquitectura: teoría e historia de un lenguaje gráfico. Dos años más tarde, en esta misma editorial, Fernando Valderrama y yo publicamos otro libro, ahora como autores, no como traductores: Infografía y arquitectura: dibujo y proyecto asistidos por ordenador. Desde 1988 hasta 2001 trabajé en el equipo editorial de las revistas A\&V Monografías de Arquitectura y Vivienda (luego simplemente AV Monografías) y Arquitectura Viva, a las órdenes de Luis Fernández-Galiano. Mis labores eran principalmente de redacción y traducción, y ocasionalmente de composición de páginas y producción. Allí aprendí casi todo lo que sé sobre el mundo editorial relacionado con la arquitectura. El resto de mi relación con editoriales de arquitectura ha sido ya como director de colección, primero con Mairea/Celeste (Madrid) y desde 2004 hasta el momento con Editorial Reverté (Barcelona), en la cual mi actividad ha sido fundamentalmente: diseñar las colecciones, decidir los títulos que se publican, hacer algunas de las traducciones y realizar toda la producción hasta el momento del envío a imprenta.

En las diferentes editoriales con las cuales ha realizado trabajos de traducción: ¿ha tenido influencia su propia 
visión como docente, al momento de sugerir la traducción de textos relevantes escritos en otros idiomas?

JCE. Después de unos primeros momentos en los cuales me limitaba a aceptar o rechazar encargos que se me proponían, aproximadamente a partir de 1990 comencé a tener una cierta influencia a la hora de proponer traducciones de textos relevantes, de las cuales a menudo terminé encargándome yo mismo. Actualmente soy asesor de diversas editoriales y, en algunos casos, cuando el libro me interesa particularmente, procuro ser yo mismo el traductor. En 2003, cuando Juan Barja dejó la dirección de ediciones Akal y decidió emprender un proyecto editorial personal, un grupo de amigos nos unimos a su idea para fundar Abada Editores, editorial en la que, además de ser socio fundador, tengo la responsabilidad, junto con Juan Miguel Hernández León, de las publicaciones de arte y arquitectura, que constituyen una parte esencial de nuestra línea editorial. Del mismo modo, formo parte del Consejo de la Editorial Universidad de Granada, para la cual he realizado también alguna traducción. Considero importante reivindicar el papel científico que desempeñan hoy algunas editoriales universitarias y que contrasta con el desprecio de que son objeto por parte de los comités oficiales de evaluación de la investigación, en los que se ha instaurado una estúpida e incomprensible veneración de la empresa privada y desvalorización de lo público. Por supuesto, creo que resulta innecesario añadir que, en todos estos procesos de evaluación, dominados por el papanatismo del Journal Citation Reports (JCR), la labor de traducción no cuenta para nada: ¿puede alguien comprender que un artículo de 8 páginas firmado por 7 autores "pese" mucho más que un libro de 500 páginas de un único autor?

JSA. Por supuesto. Mi actividad como profesor del Departamento de Composición de la Escuela Técnica Superior de Arquitectura de la Universidad Politécnica de Madrid ha sido el fundamento para toda mi actividad editorial, tanto de traductor como de director de colecciones de libros de arquitectura. Esto ha tenido más influencia en los libros editados que en los traducidos personalmente por mí. Por ejemplo, el libro Iniciación a la arquitectura, de Alfonso Muñoz Cosme lo edité específicamente para mi curso de "Introducción a la arquitectura”, en el primer año de la carrera, y lo mismo ocurrió con el de Federico García Erviti, Compendio de arquitectura legal, aunque éste no es de teoría e historia. La traducción de La arquitectura de los jardines, de Francesco Fariello, publicado primero por Mairea/Celeste y luego por Reverté, fue un encargo directamente relacionado con la asignatura
"Jardinería y paisaje", en la que prácticamente se convirtió en "libro de texto". La re-traducción de la Historia crítica de la arquitectura moderna, de Kenneth Frampton estuvo directamente relacionada con el hecho de que es uno de los libros más usados como referencia en las asignaturas de historia de la arquitectura de todas las escuelas del mundo de habla hispana. La nueva traducción y edición de Espacio, tiempo y arquitectura, de Sigfried Giedion, también estuvo motivada por la misma razón: corregir los llamativos errores de la traducción existente y publicar la última edición aparecida en inglés; de este modo, el libro vuelve a ser utilizable para el estudio de la arquitectura moderna en lengua española.

\section{Dentro del conjunto de obras que usted ha traducido: ¿ha existido la colaboración directa con los autores del texto original, para revisar pasajes específicos o actua- lizar conceptos, por ejemplo?}

JCE. En bastantes ocasiones he discutido problemas de traducción con los autores. Algunas veces ya los conocía previamente, como es el caso de Francesco Dal Co, Werner Szambien, Dominique Poulot o Roland Recht. En otros casos fue al revés: la traducción estuvo en el origen de lo que luego derivó en amistad e intereses compartidos, como ocurrió con Jean Castex o Georges Didi-Huberman. También tuve alguna breve conversación con verdaderos maestros, ya desaparecidos, que considero un privilegio haber tenido oportunidad de conocer, como Giulio Carlo Argan, Eugenio Battisti o André Chastel. Y quiero reservar un recuerdo especial para dos grandes historiadores con los cuales llegué a trabar, gracias al hecho de traducir sus obras, una amistad que sus respectivos fallecimientos interrumpieron justo cuando, en ambos casos, comenzábamos a vislumbrar proyectos de colaboración futura. Me refiero a Benedetto Gravagnuolo, de quien traduje, para Akal, su Historia del urbanismo en Europa, 1750-1990, y a Michel Baridon, referencia mundial en historia del jardín y cuyo monumental Los Jardines. Paisajistas, jardineros, poetas, conocido en Francia como "la Biblia de los jardines", traduje en tres volúmenes para Abada a lo largo de varios años.

JSA. Sí. Siempre he procurado resolver las dudas con los autores, aunque no ha sido posible en todos los casos. El primer contacto con un autor fue entre 1979 y 1980, con Christian Norberg-Schulz, pero fue más bien protocolario, no para consultarle dudas sobre la traducción.

El primer contacto importante, epistolar y personal, con un autor fue con William Curtis, cuando traduje la primera edi- 


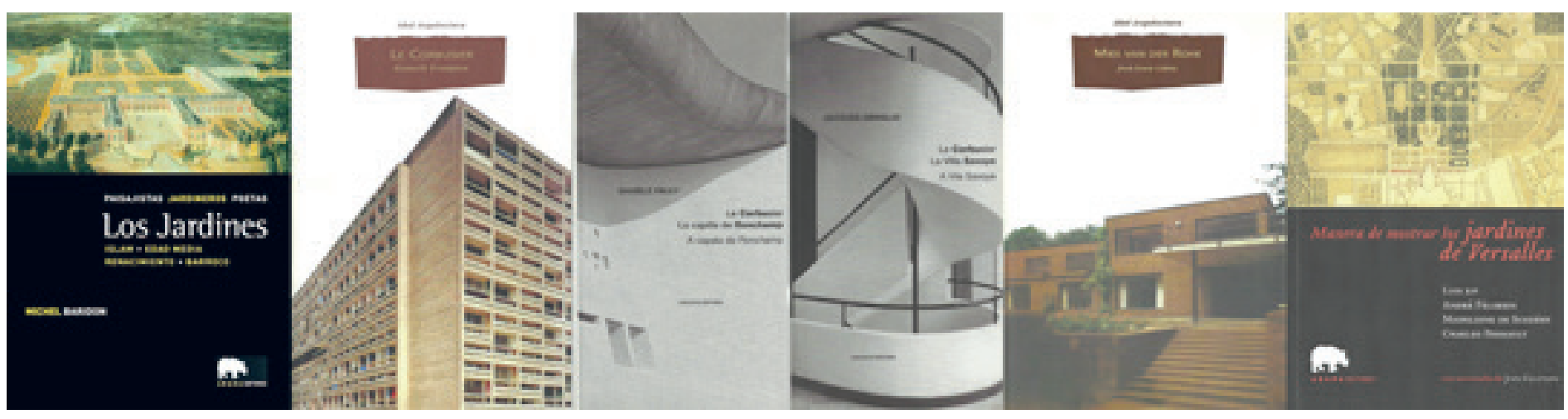

[Fig. 3] Portadas de traducciones realizadas por Juan Calatrava Escobar.

ción de La arquitectura moderna desde 1900 (1986). Conservo una carta, pero es posterior a la publicación; no hubo correspondencia durante la traducción. Con Curtis he tenido un contacto muy frecuente, que se mantiene en la actualidad. También mantuve correspondencia con Franz Schulze mientras traducía la primera edición de Mies van der Rohe: una biografía crítica (1986). Lo conservo todo: lo más interesante son un par de cartas relativas al verdadero nombre de la estatua colocada en el Pabellón de Barcelona, que en el original inglés aparecía como Evening porque el autor pensaba que el original alemán era Der Abend. Pero luego comprobó que en realidad la estatua era Der Morgen, y nos dio tiempo a cambiar el nombre en la versión española: La mañana. Del siguiente libro de Curtis, Le Corbusier: ideas y formas (1987), conservo un par de cartas relativas a un término concreto tomado de una cita, nada importante. De hecho, intenté por dos veces visitar a Curtis en su casa del sur de Francia, pero nunca lo encontré. Al final, nos conocimos personalmente en Madrid. Sobre mis inicios como traductor y mi relación con Curtis hace poco escribí un cuento que leí en la presentación de la segunda edición inglesa de su monografía de Le Corbusier, aún no traducida al español. También tengo la correspondencia del libro El espacio de la llustración, de Anthony Vidler. Lo más curioso de este caso es que el original estaba escrito en inglés, pero trata fundamentalmente sobre Francia, así que tuve que manejar dos ediciones, la inglesa y la francesa que no eran idénticas, para hacer la versión española.

La historia más interesante de mi carrera fue aquella de la re-traducción de Historia crítica de la arquitectura moderna de Kenneth Frampton. Conservo una larga, detallada y tensa correspondencia tanto con el propio Frampton como con el entonces responsable de la editorial Gustavo Gili. La historia es la siguiente: desde la primera traducción publicada en
1981, hasta la tercera publicada en 1993, habían intervenido un total de cuatro traductores: Esteve Riambau i Sauri, Aquiles González Raventós, Mª Luisa Aguado, y Santiago Castán Gómez-Calvo. Cuando en 1997 me encargaron escribir un capítulo sobre la arquitectura del siglo xx para una Historia del Arte en 4 volúmenes, releí el libro de Frampton y me di cuenta de que la traducción era malísima. Un solo ejemplo: el título del capítulo 2 de la parte II es, en inglés, "Adler and Sullivan: the Auditorium and the high rise, 1886-1895"; en la versión española aparecía como "Adler y Sullivan: el Auditorium y el gran ascenso de 1886-1895". Sin comentarios. Y así estaba todo el libro. En vista de ello, propuse a GG re-traducir todo el libro gratis, a cambio únicamente de algo que no era costumbre y que sigue sin serlo: poner el nombre del traductor en la cubierta, no sólo en la página de créditos. GG aceptó. Hice la traducción entre marzo y julio de 1997. Tuve un interesante intercambio de faxes con el propio Frampton, que aceptó prácticamente todas mis sugerencias de corrección, salvo una intrascendente, de las que conservo la lista completa. Seguramente, el error más llamativo es que decía que Henry van de Velde había asistido al CIAM de Otterlo en 1959, cuando en realidad había muerto en 1957. Aunque Frampton me dijo que pasaría todas estas correcciones a la editorial Thames and Hudson para que las incorporasen a la versión inglesa, ahora compruebo que no se ha hecho, y la última edición inglesa (2007) sigue conservando todos los errores detectados. Pero la triste anécdota de este trabajo es que, tras entregar una traducción impecable, la editorial la pasó a un supuesto departamento de "corrección de estilo" que hizo muchos cambios, cometió muchos errores y, para colmo, no conservó las pruebas en las que se habían anotado esas modificaciones. Tras mostrar mi indignación, llegamos a un acuerdo para que yo volviese a leer las pruebas de imprenta y así intentar reconstruir mi texto original. Pero esto 
ya no fue gratis. Así que el conjunto de la operación fue un fiasco económico para la editorial. Afortunadamente, el libro sigue siendo uno de los más vendidos. Con respecto a las ediciones, a partir de 1998, GG ha publicado el libro con mi traducción y con mi nombre en la cubierta. Y en 2009 apareció una nueva edición (traducción de la $4^{\mathrm{a}}$ inglesa, revisada, aumentada y actualizada, 2007). Al parecer, Frampton está preparando una nueva ampliación, pero aún no me han dicho nada en GG.

Otro autor con quien aún tengo pleno contacto es Panayotis Tournikiotis, a raíz de la traducción de su libro La historiografía de la arquitectura moderna, publicada primero por Mairea/Celeste y más adelante por Reverté. Pero a partir de aquí todo se desarrolló ya por correo electrónico, así que conservo muchísima información y correspondencia con autores posteriores como Alan Colquhoun², William Curtis³, Gillian Darley, Paul Goldberger ${ }^{4}$, Franz Schulze y Edward Windhorst ${ }^{5}$. Sobre los autores ya fallecidos en el momento de realizar la traducción de sus textos (como Francesco Fariello, Louis Kahn, Christian Norberg-Schulz, Moiséi Guínzburg y Sigfried Giedion), siempre he procurado contactar con personas de su entorno: la hija de Fariello, la esposa y traductora de Norberg-Schulz, el hijo de Giedion, etcétera. Por el contrario, nunca he tenido contacto con ciertos autores, aún vivos cuando se hacía la traducción, como John Julius Norwich, Renato De Fusco, Luciano Patetta, Alexander Tzonis, Paolo Portoghesi y Rem Koolhaas.

¿Cuáles son los principales teóricos de la traducción, o los escritores, filósofos o semiólogos que han escrito o se han referido al tema (por ejemplo: Eco, Borges, etcé-

2 Colquhoun aceptó mi sugerencia de añadir un subtítulo a la edición española, que finalmente apareció como La arquitectura moderna: una historia desapasionada. Esta edición española tiene otra curiosa anécdota: el diseño de la cubierta es tan ambiguo que durante un tiempo el libro apareció en Amazon.com como si el autor fuese yo, no Colquhoun.

3 Sobre la $3^{a}$ edición de La arquitectura moderna desde 1900, publicada en español por la propia editorial Phaidon, conservo centenares de mensajes con el autor sobre todo tipo de temas lingüísticos y editoriales.

4 Para la publicación de Por qué importa la arquitectura, el autor aceptó casi todas mis sugerencias, relativas a incluir ejemplos de monumentos que no fuesen estrictamente de la cultura occidental anglosajona, y que se extendiesen al mundo de habla hispana. El autor tuvo la amabilidad de hacer mención a ello en su prefacio a la edición española.

5 Schulze y Windhorst -autores de mi última traducción, la edición revisada de Mies van der Rohe: una biografía crítica, cuya primera edición también traduje, en 1986- han tenido la amabilidad de agradecer mis esfuerzos en la adenda al prefacio de la nueva edición española. tera), que han influenciado y estructurado su visión en torno a este oficio a lo largo de su carrera como traductor y editor?

JCE. Además de las referencias que usted menciona y que son indiscutibles, son esenciales los análisis de Walter Benjamin sobre la traducción, y justamente en Abada nos encontramos en proceso de publicación de la obra completa del gran pensador alemán. También me resultan de gran interés las reflexiones de Marcel Proust al traducir al francés a John Ruskin. De ello me ocupé personalmente para Abada editores, cuando realicé la traducción de La Biblia de Amiens de Ruskin, precedida de la introducción de Proust para su edición francesa que es casi tan larga como el original. A propósito de Proust, también he traducido dos textos suyos cortos y poco conocidos pero que son absolutamente esenciales, La muerte de las catedrales e Impresiones de un viaje en automóvil, que incluí como apéndice de un trabajo de investigación que publiqué en el libro La arquitectura y el tiempo (Abada editores).

JSA. Repasando mi biblioteca, veo que casi sólo tengo libros dedicados a la labor técnica, puramente lingüística, de la traducción y la escritura; pero hay muy pocos relacionados con la traducción literaria.

Si debo mencionar los libros que más me han servido, para traducir y escribir -además de los diversos libros de estilo de editoriales y publicaciones-, estos serían: Discurso sobre el estilo (Buffon, 2004); Segundo diario mínimo (Eco, 1994); Decir casi lo mismo: experiencias de traducción (Eco, 2008); Nadie acabará con los libros (Eco, y Carrière, 2010); Teoría y práctica de la traducción (García Yebra, 1984); Getting it published: a guide for scholars and anyone else serious about serious books (Germano, 2008); On writing (King, 2000); La escritura transparente: cómo contar historias (Lyon, 2014); El libro del español correcto: claves para hablar y escribir bien en español (Paredes García, y otros, 2012); La legibilidad: investigaciones actuales (Richaudeau, 1987); Sobre la traducción (Ricoeur, 2005); Después de Babel: aspectos del lenguaje y la traducción (Steiner, 2001); The elements of style (Strunk, 1918); On writing well: the classic guide to writing nonfiction (Zinsser, 2006).

¿Cuáles son aquellos traductores en lengua española, o también en otras lenguas, que usted admira por la calidad de su trabajo? Si es el caso, ¿con cuáles de ellos ha tenido la oportunidad de intercambiar opiniones y discutir sobre el oficio del traductor? 
JCE. A veces tenemos tendencia a destacar sólo lo malo, pero la verdad es que cada vez hay más buenos traductores de arquitectura. Citaré sólo dos, comenzando por supuesto por la infatigable labor de mi colega Jorge Sainz. Pero, además, quiero llamar la atención sobre el trabajo, menos conocido, de un arquitecto que viene realizando traducciones verdaderamente exquisitas y que no en vano es además un gran poeta: José Miguel Gómez Acosta, editor también de la estupenda revista Márgenes Arquitectura.

JSA. Como suele ocurrir, sólo se mira el nombre de un traductor cuando la traducción nos parece mala. En el mundo literario, admiro sobre todo el trabajo de Miguel Sáenz traductor de Michael Ende y Günter Grass; y el trabajo de HeIena Lozano, traductora de Umberto Eco. El trabajo de Sáenz no lo puedo comparar con el original alemán, porque no tengo suficiente conocimiento de esa lengua; pero su español es espléndido. El trabajo de Lozano, en cambio, sí puedo compararlo con el original italiano, y creo que es impecable. Mi labor de traductor se limita al campo de la arquitectura; incluso más: al de la teoría y la historia de la arquitectura. Así que no suelo hablar de este trabajo más que de manera informal con mis colegas académicos. $Y$ en este mundo académico, uno de los mejores profesionales de la traducción es, sin duda, mi colega Juan Calatrava.

\section{¿Qué le ha aportado el ejercicio de este oficio a su acti- vidad como docente y como investigador?}

JCE. Como docente, la satisfacción de poder difundir entre mis estudiantes textos de gran importancia y ver cómo gracias a mi mediación se hacían accesibles en español. Como investigador no puedo decir que esta labor haya añadido un componente específico a mi trabajo, ya que la mayor parte de las veces se trataba de obras que ya conocía en sus lenguas originales, aunque es verdad, como he dicho anteriormente, que traducir te permite sumergirte en el texto de un modo mucho más intenso, y cuando el autor de ese texto se llama Argan, Tafuri, Dal Co o Didi-Huberman eso es mucho decir. También es cierto que en muchos casos la traducción ha sido la vía que me ha permitido estrechar el contacto con investigadores de otros países.

JSA. Creo que lo más importante de traducir libros de teoría e historia de la arquitectura ha sido entender en profundidad lo que decían. Muchas veces leemos un libro en otro idioma y, al encontrarnos con algo poco claro, simplemente seguimos adelante. Cuando hay que traducirlo, esto no es posible: hay que encontrar el significado y plasmarlo en tu lengua. También creo que mi trabajo ha contribuido a aclarar un poco la terminología. Por influencia, sobre todo, del inglés, vamos incorporando al español términos que no son correctos; y al final, parece que tienden a aceptarse. El ejemplo más claro sería el inglés modernism o modernist architecture. En su origen, este término es en francés architecture nouvelle; y en alemán, neues Bauen. Todo ello dio lugar después al Movimiento Moderno. Pues bien, sigue habiendo muchos libros de arquitectura "moderna", traducidos del inglés tanto en España como en América Latina, que hablan de "modernismo" y "arquitectura modernista" cuando se refieren a la arquitectura de, por ejemplo, Le Corbusier o Mies van der Rohe; sin embargo, en buen español, esos términos tienen que ver con el Modernismo (Modernisme en Cataluña) de 1900 y primeras décadas del siglo xx, que es un estilo coetáneo al Art Nouveau y a sus variantes europeas (Modern Style, Stile Liberty, Jugendstil, Secession, etcétera). Esto ha dado lugar a que la "arquitectura posmoderna" se denomine "posmodernismo". Y este término ya parece irremisiblemente consolidado.

\section{¿Considera usted necesario que el traductor de textos de arquitectura y urbanismo sea profesional en alguna de estas disciplinas (o alguna relacionada: historia del arte, por ejemplo)? 0 , por el contrario, ¿cree usted que el dominio técnico de un idioma por parte de un traduc- tor profesional es suficiente para realizar este tipo de empresas?}

JCE. Lo considero absolutamente indispensable y la prueba de ello, a contrario, es la gran cantidad de verdaderos disparates que se encuentran en traducciones castellanas de textos especializados. No se trata sólo de que el traductor no sepa nada de la materia, pues eso tiene remedio si detecta que hay cosas que no funcionan y entiende que debe informarse más: por ejemplo, sólo era necesario un poco de sentido común para darse cuenta de la barbaridad que era hablar de las incomodidades que afrontaban los peregrinos medievales en unos caminos "llenos de pólvora", como dice la traducción española de un estupendo libro de historia, confundiendo "poudre", el polvo en general, con "poudre à canon", es decir, la pólvora como explosivo. El problema es la gran cantidad de pseudo-traductores que, desde la osadía que da la ignorancia, no tienen el más mínimo interés en profundizar su información ni en hacer bien su trabajo, a menudo con el reiterado argumento de "...para lo que pagan”. Aún recuerdo, por ejemplo, una traducción lamentable, que sigue 

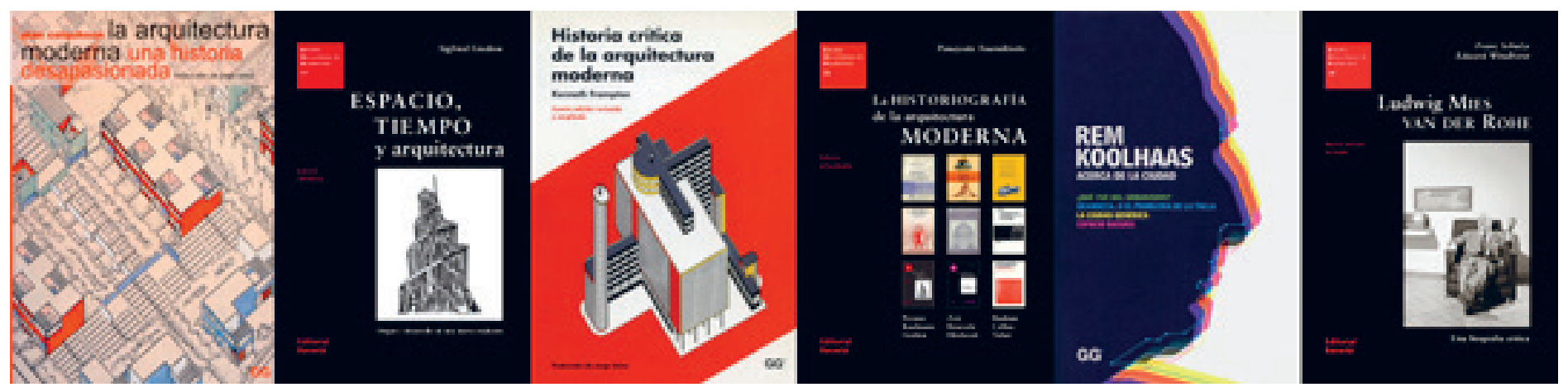

[Fig. 4] Portadas de traducciones realizadas por Jorge Sainz Avia.

circulando, en la que las villas de Andrea Palladio aparecían en español como "ciudad Rotonda", "ciudad Maser", etc., es decir: villa traducido como si fuera ville. Otro ejemplo que pone los pelos de punta es la insufriblemente mala traducción de la edición en castellano del Mensaje a los estudiantes de arquitectura de Le Corbusier. Aunque con notables excepciones, es paradójica la mala suerte que en general han tenido los libros del gran maestro de la arquitectura del siglo XX al verterse al español, hasta el punto de que recientemente Josep Quetglas, nuestro mayor "corbusieriano", hacía un llamamiento a la realización de nuevas traducciones de algunas de las obras teóricas de Le Corbusier. No quiero decir con ello que los textos de una materia dada sólo puedan ser traducidos por especialistas en la misma, aunque sin duda eso sería el ideal. Los buenos profesionales de la traducción deben ser versátiles, y simplemente hay que reclamar de ellos justamente eso, profesionalidad, lo que incluye la curiosidad intelectual o, al menos, la autoexigencia de comprobar su traducción con otras referencias del tema objeto de la misma. Otro problema aparte, sobre el que habría mucho que hablar, es la necesidad tan evidente como a menudo incumplida de que los traductores al español sepan, antes que nada, español. Pero esto es un problema general: sólo hay que leer los periódicos para darse cuenta cómo la precisión del lenguaje es algo que ya sólo nos preocupa a unos cuantos dinosaurios. Personalmente, hay dos manías actuales que me molestan de modo especial: el uso arbitrario de los signos de puntuación (la habitual "siembra" de comas allá donde caigan) y la no concordancia entre verbo y sujeto (decir, por ejemplo: "El problema de las traducciones son que..."). Son batallas ya perdidas, pero los revisores editoriales siguen teniendo un papel muy importante que jugar.

JSA. Al menos en el caso de mi ámbito de trabajo, creo que un buen traductor ha de tener una sólida formación en el campo de conocimiento del que quiere traducir. Si no lo tiene, tendrá que dedicar mucho tiempo a entender algunas cosas o a buscarlas en otros libros, y no simplemente en diccionarios. Además, el tiempo suele ser muy escaso en los encargos de traducción. Es difícil que un profano traduzca espontáneamente floor slab por "forjado"; y elevation por "alzado". Pero seguramente lo más importante es tener curiosidad: preguntarse y buscar, qué es lo que realmente se quiere indicar con un término o una idea. $Y$ eso suele llevar tiempo, que es lo que no sobra. Algunas de las traducciones de este tipo, hechas por empresas supuestamente especializadas, suelen ser espantosas. Por eso son baratas.

A día de hoy, ¿cuáles autores (teóricos, historiadores, críticos, arquitectos, urbanistas, etc.) cree usted que son poco conocidos -o desconocidos- en las escuelas de arquitectura de España y América Latina, debido a la ausencia de traducciones de sus obras?

JCE. La lista sería muy larga y además se va ampliando en lugar de disminuir, ya que, por desgracia, cada vez más las editoriales se lo tienen que pensar dos veces antes de afrontar el elevado coste de una traducción, en un mercado editorial que cada vez es más restringido por dos razones: la práctica desaparición de la curiosidad intelectual de los estudiantes universitarios y la proliferación de la piratería. Como anécdota, contaré que hace poco no salía de mi asombro cuando un estudiante me envió, con total desparpajo, un mensaje preguntándome si sabía dónde podía descargarse un libro que necesitaba para un trabajo. Le respondí que si se le había pasado alguna vez por la mente la fácil solución de entrar en una librería y comprarlo, pues no se trataba de ninguna obra descatalogada. Por supuesto, no recibí contestación. 
JSA. Creo que a estas alturas del siglo XXI hay pocos autores que no tengan sus ideas publicadas en español. Durante mucho tiempo hubo una grave falta de traducciones del alemán, lo que nos privó de buena parte de las ideas del Movimiento Moderno inicial (neues Bauen). Pero ahora se puede encontrar prácticamente todo. Dos ejemplos de este cambio serían las recientes traducciones de dos obras muy mencionadas, pero que no existían en español: Obra de los pasajes de Walter Benjamin (Abada, 2013) y El estilo de Gottfried Semper (Azpiazu, 2013). Otro factor relevante es que cada vez más personas, sobre todo en el ámbito universitario, tienen un conocimiento del inglés lo suficientemente bueno como para manejarse bien con los textos referidos a su disciplina, aunque no puedan hacerlo, por ejemplo, con textos literarios. Esto hace que surjan dudas sobre la conveniencia de traducir algunas obras del inglés, sobre todo si son muy voluminosas y por lo tanto costosas de traducir, porque se piensa que la mayoría de los destinatarios lo van a poder leer directamente en inglés. Pero tal vez el hecho de que no existan algunos libros en español no es tan grave como el de que no se reimpriman los ya traducidos. La crisis económica de finales de la década de 2000 ha hecho que algunas editoriales no puedan afrontar la reimpresión de algunas obras fundamentales ${ }^{6}$.

¿Qué autores (teóricos, historiadores, críticos, arquitectos, urbanistas, etc.), o qué obras le gustaría traducir, incluso si el idioma original es un idioma que usted no domina, pero que conoce por una traducción al inglés, por ejemplo?

JCE. De nuevo, la lista sería muy amplia. Siempre he lamentado, por ejemplo, la ausencia de una edición castellana de L'Architettura del Manierismo, de Manfredo Tafuri, del apasionante y provocador Antirinascimento de Eugenio Battisti, o, de fecha más reciente, del extraordinario Landscape and Memory de Simon Schama. También podría citar muchos libros inéditos en español, de grandes investigadores o pensadores cuya obra siempre ha sido para mí una referencia, como por ejemplo -y sin ningún ánimo de ex-

6 Tal es el caso de: Historia de la arquitectura moderna e Introducción a la arquitectura, de Leonardo Benevolo; Los ideales de la arquitectura moderna, de Peter Collins; La arquitectura moderna, de Alan Colquhoun; La arquitectura occidental, de Robert Furneaux Jordan; Arquitectura occidental, de Christian Norberg-Schulz; Historia de la arquitectura, de Patrick Nuttgens; Breve historia de la arquitectura europea, de Nikolaus Pevsner; Arquitectura contemporánea, de Manfredo Tafuri y Francesco Dal Co; Historia de la arquitectura occidental, de David Watkin; o Historia de la arquitectura moderna, de Bruno Zevi. haustividad-: Maurice Halbwachs, Jean Starobinski, Georges Teyssot, Jean-Louis Cohen, Tim Benton, Roberto Gargiani, Kenneth Frampton, Werner Oechslin, Joseph Rykwert, entre otros. Y, por supuesto, numerosos textos de Le Corbusier que o no han sido nunca traducidos o lo han sido muy mal, como ya señalé.

JSA. No sabría decir. Si tuviese tiempo y dinero, me gustaría traducir y editar los libros de Christian Norberg-Schulz que aún no se han publicado en español; y re-traducir alguno ya publicado, muy mal traducido. También me gustaría traducir la nueva edición de Le Corbusier: ideas and forms de William Curtis, pues en su momento ya traduje la primera edición. Pero es un texto muy extenso, y ahora no tengo tiempo.

En Francia, es ampliamente reconocido el rol que desde la academia y el campo editorial supo dar Françoise Choay al ejercicio de la traducción de textos fundamentales de la arquitectura, el urbanismo, y el patrimonio. En el caso de España y de América Latina, ¿qué personajes del mundo académico y/o intelectual cree usted que influyeron en el impulso del oficio, y en su reconocimiento profesional y social?

JCE. Por supuesto, el papel de Françoise Choay ha sido absolutamente relevante en este campo. Tengo el precioso recuerdo de una larga y agradable conversación con ella sobre estos temas allá por finales de los 90, en su domicilio de la rue Saint-Guillaume de París, justo al lado de la mítica Maison de Verre de Pierre Chareau. En España cabría destacar el papel pionero de Luis Fernández Galiano o, actualmente, la extraordinaria labor que lleva a cabo desde hace décadas, desde diversas plataformas editoriales, Jorge Sainz, a quien debo expresar mi admiración.

JSA. No sé si en el reconocimiento profesional y social, pero en cuanto al impulso a la traducción de libros de arquitectura en España, creo que ha sido muy importante la labor del difunto Ignasi de Solà-Morales en la editorial Gustavo Gili (Barcelona) y de Luis Fernandez-Galiano en la editorial Hermann Blume (Madrid). También realizó una importante labor Fernando Márquez en El Croquis Editorial (Madrid y San Lorenzo del Escorial), con su colección "Biblioteca de arquitectura". En estos momentos, creo que también es digna de encomio la labor de traducción fomentada por Abada Editores. Sobre América Latina no tengo información. 


\begin{abstract}
¿Podría citar textos recientes sobre arquitectura y/o urbanismo (investigaciones, tesis, ensayos, etc.) escritos en español y aun sin traducir a otros idiomas, que usted considere que ameritan ser conocidos por los lectores especializados de otras lenguas?
\end{abstract}

JCE. La lista sería también larga, y en este caso tengo que decir que afortunadamente, porque la investigación española en arquitectura y urbanismo ha progresado mucho en los últimos años. Sin esforzarme mucho me viene fácilmente a la cabeza una docena de libros que merecerían ser inmediatamente traducidos a otras lenguas. Pero, en aras a la brevedad, si tuviese que elegir un solo ejemplo optaría por el sólido grupo que componen los cuatro libros de Carlos García Vázquez, arquitecto y catedrático en la Escuela de Arquitectura de Sevilla: Berlín Potsdamer Platz, Ciudad Hojaldre, Antípolis y Teorías e historia de la ciudad contemporánea.

JSA. Hay infinidad de libros y tesis doctorales elaborados en mi entorno académico que merecerían ser traducidos al menos, al inglés. Sin embargo, las editoriales anglosajonas, ya sean comerciales o institucionales, no muestran interés alguno por la producción académica en lengua española. Las pocas excepciones que conozco son de autores de un inmenso prestigio y con buenos contactos en el mundo intelectual y editorial anglosajón. Un par de ejemplos serían: Luis Fernández-Galiano, Fire and memory: on architecture and energy (Cambridge, Massachusetts: MIT Press, 2000); Rafael Moneo, Theoretical anxiety and design strategies in the work of eight contemporary architects (Cambridge, Massachusetts, y Londres: MIT Press, 2004).

En mi entorno inmediato, considero que hay un libro que debería traducirse al francés, pero tampoco las editoriales galas muestran mucho interés por los autores españoles. Se trata de: José Ramón Alonso Pereira, El París de Le Corbusier (Reverté: Barcelona, 2015).

¿podría contarnos alguna anécdota que se hayan presentado a lo largo de su trayectoria con los editores, los autores, o con sus colegas traductores?

JCE. Como es fácil imaginar, en una labor tan dilatada me ha ocurrido de todo. En general, mis relaciones con los editores o las instituciones que me han encargado traducciones y con los autores a los que debía traducir han sido positivas y los buenos recuerdos predominan sobre alguno que otro no tan bueno.
JSA. Algunas anécdotas están incluidas en el cuento que escribí con motivo de la presentación de la segunda edición inglesa de la monografía de Curtis sobre Le Corbusier. Puedo mencionar algunas otras, polémicas o curiosas.

Por ejemplo, la re-traducción de Espacio, tiempo y arquitectura de Sigfried Giedion se tuvo que hacer desde cero, a partir de la $5^{a}$ y definitiva edición norteamericana, ya que la versión existente en español parecía haberse hecho desde el italiano: por ejemplo, decía "Seiscientos" en lugar de "siglo xvil" y cosas por el estilo. Además, la edición existente tenía algunas cosas muy anacrónicas, cómo lo de traducir los nombres de pila; y así, decía "Francisco" Lloyd Wright, "Carlos Eduardo" Jeanneret o "Álvaro" Aalto.

También en la edición española de Por qué importa la arquitectura, de Paul Goldberger, la labor de traducción se amplió a la de redacción, y el autor incluyó algunos ejemplos procedentes de la cultura de habla hispana que no aparecen en la versión original inglesa.

Sobre mis traducciones de Rem Koolhaas recuerdo varias. Delirio de Nueva York, el título que le puse a Delirious New York, fue muy criticado por algunas personas de mi entorno académico. Sin embargo, a mí me pareció una buena solución, en vista de que en otros idiomas tampoco se había hecho una traducción literal ("delirante nueva York"). La versión francesa es New York délire; y la italiana mantiene el inglés original. El título del ensayo Singapore songlines se decidió de acuerdo con el responsable editorial de Gustavo Gili. Dada la polisemia de "songlines", entre varias opciones se eligió la que tenía mejor ritmo en español: el endecasílabo Sendas oníricas de Singapur. El título de otro de sus ensayos, Bigness, or the problem of large, recibió críticas, por elegir la palabra española "grandeza". Hay que decir, en primer lugar, que bigness es comprensible en inglés, pero no está en la mayoría de los diccionarios: es un invento compuesto de big ("grande", físicamente) y la terminación -ness ("cualidad de"). Y en segundo lugar, la primera acepción de "grandeza" según el diccionario de la Real Academia Española es "tamaño excesivo de algo respecto de otra cosa del mismo género".

Entre los cambios tecnológicos que han impactado el universo del libro, y de todos los campos que lo rodean, ¿cuál o cuáles considera usted que han sido los principales cambios, positivos o negativos, que han repercutido en la traducción de textos fundamentales de arquitectura y urbanismo? 
JCE. Es evidente que el gran cambio ha venido dado por el universo de Internet. Éste tiene indiscutibles ventajas para el investigador y también para esa parcela especial de la investigación que es la traducción. Pero también efectos perversos, como la tentación de la comodidad y la pérdida de la tensión intelectual, sustituida por una especie de "surfeo" sobre los aspectos más superficiales de la cultura. Creo que el tema es de gran complejidad, y yo tampoco soy un experto en el mismo sino más bien todo lo contrario, pero quizás se podría resumir diciendo que Internet ofrece ilimitadas posibilidades de enriquecimiento y de recursos, pero también numerosos daños colaterales y efectos no deseados. A otro nivel, está, por supuesto, el ya citado problema de la piratería del libro, sobre el que hay que entender de una vez que no es un tema meramente económico sino cultural. Como ya he señalado, las descargas ilegales de libros están resultando letales al lastrar la iniciativa de los editores a la hora de abordar programas editoriales de una cierta ambición. Es curioso que personas a las que jamás se les pasaría por la mente la idea de robar algo en un supermercado se descarguen alegremente cientos de libros, que posiblemente nunca leerán, sin tener conciencia de que, en el fondo, estamos hablando de lo mismo.
JSA. Para la labor concreta de traducir, tener toda esa información accesible desde el mismo ordenador en el que estamos escribiendo es una bendición. Es cierto que algunos diccionarios impresos siguen conteniendo más soluciones que los que están disponibles en Internet, pero para la mayoría de los casos estos últimos son más que suficientes. Aparte de los significados, la posibilidad de encontrar imágenes de los términos dudosos o ambiguos facilita mucho la labor del traductor. Y lo mismo puede decirse de la información enciclopédica: datos que nos puedan ayudar a contextualizar un relato o una descripción. Esto es especialmente interesante para los libros académicos y sus bibliografías, ya que parte de la labor de un buen traductor académico es encontrar las versiones españolas de los libros citados en otros idiomas. Por su parte, los programas de escritura cada vez ofrecen más ayudas al usuario; y bien utilizados, son realmente eficaces para encontrar erratas ortográficas o errores gramaticales. Lo importante es que no hagan nada de modo automático, sino que nos sugieran soluciones y nosotros decidamos. Me consta además que existen programas específicos para traducir, que detectan construcciones o denominaciones que se repiten una y otra vez, y permiten insertarlas con un solo clic. Seguramente son muy útiles, pero yo no los he utilizado.

\section{Algunas de las principales traducciones realizadas por Juan Calatrava Escobar}

AA.W. 1980. Arte, arquitectura y estética en el siglo XVIII. Pierre Francastel, Rosario Assunto, Giulio Carlo Argan, Manfredo Tafuri y Georges Teyssot. Madrid: Akal.

Szambien, Werner. 1993. Simetría, gusto, carácter. Teoría y terminología de la arquitectura en la época Clásica, 1550-1800. Madrid: Akal.

Vidler, Anthony. 1994. Ledoux, Madrid: Akal.

Castex, Jean. 1994. Renacimiento, barroco y clasicismo. Historia de la arquitectura, 1420-1720. Madrid: Akal.

Cohen, Jean-Louis. 1998. Mies van der Rohe, Madrid: Akal.

Gravagnuolo, Benedetto. 1998. Historia del urbanismo en Europa, 1750-1960. Madrid: Akal.

Frampton, Kenneth. 2000. Le Corbusier, Madrid: Akal.

Midant, Jean-Paul (dir.). 2004. Diccionario Akal de la arquitectura del siglo XX. Madrid: Akal.

Argan, Giulio Carlo. 2006. Walter Gropius y la Bauhaus. Madrid: Abada.

Ruskin, John. 2006. La Biblia de Amiens. Madrid: Abada.

Dal Co, Francesco. 2011. El tiempo y el arquitecto. Frank Lloyd Wright y el Museo Guggenheim. Madrid: Abada. 


\section{Algunas de las principales traducciones realizadas por Jorge Sainz Avia}

Norberg-Schulz, Christian. 1980. Intenciones en arquitectura. Barcelona: Gustavo Gili. En colaboración con Fernando González Fernández de Valderrama. [ed. orig. o de ref.: 1967]

Curtis, William J.R. 1986. La arquitectura moderna desde 1900. Madrid: Hermann Blume. [ed. orig. o de ref.: 1982]

Vidler, Anthony. 1997. El espacio de la llustración: la teoría arquitectónica en Francia a finales del siglo XVIII. Madrid: Alianza. [ed. orig. o de ref.: 1987] Frampton, Kenneth. 1998 [2009]. Historia crítica de la arquitectura moderna. Barcelona: Gustavo Gili. [ed. orig. o de ref.: 1980] [ed. rev. y amp.: / 1985 / 1992 / 2007]

Tournikiotis, Panayotis. 2001. La historiografía de la arquitectura moderna: Pevsner, Kaufmann, Giedion, Zevi, Benevolo, Hitchcock, Banham, Collins, Tafuri. Madrid: Mairea / Celeste. [2ª edición: Barcelona: Reverté, 2014] [ed. orig. o de ref.: 1999]

Kahn, Louis. 2003. Louis Kahn: escritos, conferencias y entrevistas. El Escorial: El Croquis Editorial. [ed. orig. o de ref.: 1991]

Koolhaas, Rem. 2004. Delirio de Nueva York. Barcelona: Gustavo Gili. [ed. orig. o de ref.: 1978 / 1994]

Colquhoun, Alan. 2005. La arquitectura moderna: una historia desapasionada. Barcelona: Gustavo Gili. [ed. orig. o de ref.: 2002]

Koolhaas, Rem. 2006. La ciudad genérica. Barcelona: Gustavo Gili. [ed. orig. o de ref.: 1997]

Giedion, Sigfried. 2009. Espacio, tiempo y arquitectura: origen y desarrollo de una nueva tradición. Barcelona: Reverté. [ed. orig. o de ref.: 1941; 1969]

Schulze, Franz y Edward Windhorst. 2016. Ludwig Mies van der Rohe: una biografía crítica. Barcelona: Reverté. [ed. orig. o de ref.: 2012]

Juan Calatrava Escobar es doctor en Historia del Arte y Licenciado en Derecho por la Universidad de Granada. Ha sido Profesor Titular de Historia de la Arquitectura en la Escuela Técnica Superior de Arquitectura de la Universidad Politécnica de Madrid y actualmente es catedrático de Composición arquitectónica en la E.T.S. de Arquitectura de la Universidad de Granada, institución en la cual fue subdirector entre 1994 y 2004, y director entre 2004 y 2010. Fue Gestor de Proyectos de Investigación en el Ministerio de Ciencia y Tecnología entre septiembre de 2001 y febrero de 2004, ejerciendo funciones de Secretario de la Comisión de investigación en Historia del Arte y de la Arquitectura. Profesor en diversos programas de máster y de doctorado en España, Italia y Francia, ha sido profesor invitado en Roma, Niza, Venecia y Nápoles. Ha realizado estancias como investigador invitado en Roma, París (Collège de France y École des Hautes Études en Sciences Sociales) y Montréal (Canadian Center of Architecture). Ha sido ponente y miembro del comité científico en numerosos congresos nacionales e internacionales.

$<$ http://www.ugr.es/ compoarq/compoarq_archivos/profesores/jcalatrava_archivos/jcalatrava_cv.htm>
Jorge Sainz Avia es doctor en Arquitectura de la Universidad Politécnica de Madrid - UPM (1985), con una tesis doctoral titulada Relaciones entre categorías gráficas y categorías arquitectónicas en el ámbito de la cultura moderna. Arquitecto de la Escuela Técnica Superior de Arquitectura de la Universidad Politécnica de Madrid (1980), es profesor titular de dicha universidad en el Departamento de Composición Arquitectónica (desde 1987). Ha sido redactor de las revistas AV Monografías y Arquitectura Viva (1988-2001); director de la colección "Manuales Universitarios de Arquitectura" publicada por Mairea Libros y Celeste Ediciones en Madrid (1999-2001); y director de las colecciones "Estudios Universitarios de Arquitectura" (desde 2004), "Manuales Universitarios de Edificación" (desde 2007) y "Documentos de Composición Arquitectónica" (desde 2012), publicadas por Editorial Reverté en Barcelona. $<$ http://composicion.aq.upm.es/Personales/Jorge\%20Sainz/Jorge $\% 20$ Sainz\%20Avia.html 